\title{
Targeting the Calmodulin-Regulated ErbB/Grb7 Signaling Axis in Cancer Therapy
}

\author{
Antonio Villalobo ${ }^{1}$, Irene García-Palmero ${ }^{1}$, Silviya R. Stateva ${ }^{1}$, and Karim Jellali ${ }^{2}$ \\ ${ }^{1}$ Department of Cancer Biology, Instituto de Investigaciones Biomédicas, Consejo Superior de Investigaciones \\ Científicas and Universidad Autónoma de Madrid. c/ Arturo Duperier 4, Madrid, Spain. \\ ${ }^{2}$ Centre of Biotechnology of Sfax, Sidi Mansour Road Km 6, Sfax, Tunisia
}

Received, March 5, 2013; Revised, March 30, 2013; Accepted, April 7, 2013; Published, April 8, 2013.

\begin{abstract}
Signal transduction pathways essential for the survival and viability of the cell and that frequently present aberrant expression or function in tumors are attractive targets for pharmacological intervention in human cancers. In this short review we will describe the regulation exerted by the calciumreceptor protein calmodulin $(\mathrm{CaM})$ on signaling routes involving the family of ErbB receptors - highlighting the epidermal growth factor receptor (EGFR/ErbB1) and ErbB2 - and the adaptor protein Grb7, a downstream signaling component of these receptors. The signaling mechanism of the ErbB/Grb7 axis and the regulation exerted by $\mathrm{CaM}$ on this pathway will be described. We will present a brief overview of the current efforts to inhibit the hyperactivity of ErbB receptors and Grb7 in tumors. The currently available information on targeting the CaM-binding site of these signaling proteins will be analyzed, and the pros and cons of directly targeting CaM versus the CaM-binding domain of the ErbB receptors and Grb7 as potential anti-cancer therapy will be discussed.
\end{abstract}

This article is open to POST-PUBLICATION REVIEW. Registered readers (see "For Readers") may comment by clicking on ABSTRACT on the issue's contents page.

\section{INTRODUCTION}

The ErbB receptors form a subfamily of RTKs that includes four members: EGFR/ErbB1/HER1, ErbB2/neu/HER2, ErbB3/HER3 and ErbB4/HER4. These receptors present three distinct zones: an extracellular region with two cysteine-rich domains and containing the ligand-bind site; a single membrane-spanning segment; and an intracellular region composed by a JM domain that plays an essential role in receptor activation, the tyrosine kinase catalytic domain, and a C-terminal tail containing a set of tyrosine residues that are autophosphorylated upon receptor activation (1-4).

The ErbB receptors share an extensive family of polypeptide ligands that are either very promiscuous or have relative or absolute preference for specific receptor subtypes, orchestrating in this manner a variety of signaling events to accomplish differentiated cellular responses $(5,6)$. These receptors form homo- or hetero-dimers upon ligand binding. This process induces a series of conformational changes that result in the activation of their intrinsic tyrosine kinase followed by the auto(trans)-phosphorylation of tyrosine residues (14). The most likely mechanism for the liganddependent activation of these receptors is the formation of an asymmetric dimer involving the allosteric interaction of the proximal and terminal regions of two apposed tyrosine kinase domains (7). Although ErbB2 does not have ligand-binding capacity and ErbB3 presents a non-functional tyrosine kinase domain, they form active ErbB2/ErbB3 hetero-dimers (8).

The phospho-tyrosine residues in the active receptors act as docking sites for adaptor proteins or transducing enzymes harboring $\mathrm{SH} 2$ or PTB domains, initiating in this manner complex networks of signaling events $(2,4,9,10)$. Thereafter, the ligand/receptor complexes at the plasma membrane are internalized in clathrincoated pits. The receptors are subjected to ubiquitination by the E3 ubiquitin-protein ligase c$\mathrm{Cbl}$ and sorted in endosomal vesicles where they continue generating signals. Afterwards they are proteolytically degraded via the lysosomal pathway, previous de-ubiquitination at the proteasome, or directly processed via this pathway. Alternatively, the receptors are recycled back to the plasma membrane (11-13).

The ErbB receptors participate in the control of an extensive variety of cellular functions, most prominently stimulating cell proliferation, but in

Correspondence Author: Prof. Antonio Villalobo, Instituto de Investigaciones Biomédicas CSIC-UAM, c/ Arturo Duperier 4, E-28029 Madrid, Spain; E-mail: antonio.villalobo@iib.uam.es 
addition they control differentiation, cell polarity, cell survival mechanisms, the prevention or induction of apoptosis, and cell motility (14-19). These processes are frequently altered in neoplastic cells leading to cancerogenesis, tumor progression and the development of metastasis (18).

Grb7 is an adaptor protein that participates in signal transduction events initiated from many active RTKs located at the plasma membrane, including the ErbB receptors, or from cytosolic tyrosine kinases such as FAK. Grb7 forms part of a mammalian family of adaptors that also includes Grb10 and Grb14 (20-24). These proteins are phylogenetically related to the Mig10 protein from Caenorhabditis elegans that is involved in the regulation of embryonic neural cell migration (25, 26).

The human GRB7 gene maps at the $17 \mathrm{q} 12$ q21.1 locus in the large arm of chromosome 17 and encodes a 532 amino acids modular protein. This protein harbors an N-terminal PR domain; a central GM region (for Grb and Mig10) that includes a RA domain, a PH domain, and a BPS domain (for between $\underline{\mathrm{PH}}$ and $\underline{\mathrm{S}} \mathrm{H} 2$ ); and a $\mathrm{SH} 2$ domain located in its C-terminal segment (20-24). In human tumor cells Grb7 is frequently co-amplified with ErbB2 and other neighbor genes forming the ERBB2 amplicon (24).

Similar to other adaptor proteins, Grb7 does not have intrinsic enzymatic activity but plays important roles participating in many signaling pathways. Grb7 docks via its $\mathrm{SH} 2$ domain at phospho-tyrosine residues in active RTKs, FAK, and other phospho-proteins. Upon recruitment by FAK or the EphB1 receptor Grb7 is phosphorylated and signals to control cell migration processes $(27,28)$. In human cancers including for example breast, stomach, esophagus and ovary - the overexpression of Grb7, its coamplification with ErbB2, and/or the expression of an aberrant truncated variant denoted Grb7V is known to contribute to the invasiveness and spread of metastatic tumor cells (29-33).

In addition to its well-known implication in cell migration, Grb7 plays additional roles in signaling pathways controlling other important physiological functions. This includes the control of cell proliferation, as demonstrated by disrupting Grb7 expression with siRNA or shRNA (34-36), treating cells with a cell-permeable inhibitory peptide targeting Grb7 (37), mutating the FAKmediated Grb7 phosphorylation sites (34), or deleting the CaM binding site of Grb7 (38). On the other hand, Grb7 is also an RNA-binding protein that interacts via its PR domain with the 5'-UTR of
mRNAs regulating translational processes with the intervention of netrin- 1 and FAK, and participating as well in the storage of mRNAs in stress granules under a variety of environmental conditions unsuitable for appropriate protein translation (39, 40). Additionally, we have demonstrated that Grb7 participates in the control of angiogenesis in vitro (41), and in vivo determining the extent and functional performance of the tumor-associated vasculature using an experimental model of glioma and MRI (38).

\section{CALMODULIN}

Many $\mathrm{Ca}^{2+}$-regulated cellular functions are controlled by $\mathrm{CaM}$, a small $\mathrm{Ca}^{2+}$-binding sensor protein harboring four $\mathrm{Ca}^{2+}$-binding sites that is ubiquitously present in all known eukaryotic cells and is highly conserved across vertebrate species albeit CaMs from some lower eukaryotes only have three functional $\mathrm{Ca}^{2+}$-binding sites $(42,43)$. The transient increase in the cytosolic concentration of free $\mathrm{Ca}^{2+}$ induced by many agonists, including mitogenic growth factors, results in the progressive formation of the $\mathrm{Ca}^{2+} / \mathrm{CaM}$ complex at increasing $\mathrm{Ca}^{2+}$ levels in living cells (44). Upon $\mathrm{Ca}^{2+}$ binding $\mathrm{CaM}$ changes its conformation exposing hydrophobic amino acids that favor its interaction with more than one hundred target proteins modulating their activities $(42,43)$. The central helical segment of $\mathrm{CaM}$ appears to wrap around the CaM-BD of some target proteins upon $\mathrm{Ca}^{2+}$ binding. The number of calcium ions bound to $\mathrm{CaM}$ required for efficient interaction with distinct targets varies for each protein, as experimentally demonstrated using peptides corresponding to the CaM-BDs of distinct proteins (45). For example, only two $\mathrm{Ca}^{2+}$ bound to $\mathrm{CaM}$ at their high affinity C-terminal sites are enough to activate CaMK-II (46). Nevertheless, $\mathrm{Ca}^{2+}$-free $\mathrm{CaM}$ (apo-CaM) is also able to bind and regulate many target proteins (47). The CaM-BDs of diverse target proteins often correspond to an amphipathic $\alpha$-helix with positively charged and hydrophobic amino acid residues usually distributed at opposite sides of the helix, or $\mathrm{Ca}^{2+}$-independent and $\mathrm{Ca}^{2+}$-dependent IQ motifs (47-49). Diverse molecular mechanisms for recognizing distinct $\mathrm{CaM}$-dependent target proteins by CaM have been described (50).

\section{Targeting calmodulin in cancer}

Inhibition of $\mathrm{CaM}$ has been thought to have potential therapeutic effects in cancer $(49,50)$ because of its suppressing action on cell 
proliferation and/or their capacity to revert the multi-drug resistance tendency of many tumor cells (51-54). A great variety of CaM antagonists have been described and their mechanisms of action established (55-59). This includes CaM inhibitors isolated from plant and animal products (60). CaM antagonists, however, negatively affect the proliferation of both normal and tumor cells, and to complicate matters in some instances these compounds have been reported to be less effective in transformed than in normal cells because of alterations in some CaM-dependent pathways in the former (61). Thus, as CaM is essential in all eukaryote cells for the regulation of a myriad of vital cellular functions, the widespread use of $\mathrm{CaM}$ antagonists as chemotherapeutic agents against cancer in a clinical setting is expected to be problematic.

Therefore, it could be of interest to explore alternative strategies, such as the potential efficacy of targeting the CaM-binding region(s) of selected CaM-binding proteins relevant for the proliferation of tumor cells or other essential functions for tumor progression and metastatic spread. In the following sections, we shall discuss how targeting the CaMdependent ErbB/Grb7 axis at the CaM-BD of ErbB receptors and/or Grb7 could facilitate new therapeutic approaches to fight cancer.

\section{ErbB RECEPTORS AND CALMODULIN}

The $\mathrm{Ca}^{2+} / \mathrm{CaM}$ complex controls the functionality of ErbB receptors - particularly the EGFR and ErbB2 - by a dual mechanism, either implicating CaM-dependent kinases that phosphorylate and indirectly control their activity, down-regulation, trafficking and fate; or by directly binding to the cytosolic JM region of the receptor regulating in this manner its ligand-dependent activation (62).

Our group obtained the first experimental evidence for CaM binding to the EGFR in a $\mathrm{Ca}^{2+}$ dependent manner in rat liver more than twenty years ago (63). The CaM-BD (residues 645-660) was subsequently located at the cytosolic JM region of human EGFR $(64,65)$ (see Figure 1a). Furthermore, the occurrence of CaM/EGFR complexes in living cells was established, and the possible functional implication of this interaction for ligand-dependent activation of the receptor was determined (66-71). The recent engineering of vertebrate conditional CaM-knockout cell lines (72) has been an important breakthrough to obtain further evidence of the positive regulatory action that the $\mathrm{Ca}^{2+} / \mathrm{CaM}$ complex exerts on the liganddependent activation of the EGFR in living cells without the need to use CaM antagonists, as these compounds could have unwanted off-target side effects (73).

The CaM-BD appears to be highly conserved in all ErbB receptor family members except in ErbB3 that lacks intrinsic tyrosine kinase activity (74), underscoring the relevance of this domain for its activation. High affinity binding of $\mathrm{Ca}^{2+} / \mathrm{CaM}$ to peptides corresponding to the sequences of the proposed CaM-BD of all the ErbB receptors has been determined, except for the ErbB3 peptide that presented lower affinity (68). In the ligand-free EGFR the CaM-BD appears to play an autoinhibitory role because of the electrostatic interaction of this region with the inner leaflet of the plasma membrane, preventing in this manner the ligand-independent constitutive activation of the receptor $(68,71)$.

It has been experimentally established that $\mathrm{CaM}$ also binds to ErbB2 in a $\mathrm{Ca}^{2+}$-dependent manner modulating its tyrosine kinase activity, the downstream signaling pathways of the receptor and cell growth $(75,76)$. Nevertheless, it appears that $\mathrm{Ca}^{2+} / \mathrm{CaM}$ and apo-CaM interact with ErbB2, as CaM binds to ErbB2 not in one but in two near-by sites, respectively located at the cytosolic JM region (residues 676-689) and at a more distally located segment (residues 714-732) (76). The 676689 segment was proposed to be the site of interaction for apo-CaM, while both the 676-689 and 714-732 segments contribute to the $\mathrm{Ca}^{2+}$ dependent binding (76).

In addition to the canonical signaling functions exerted by ErbB receptors when located at the plasma membrane and/or after internalization from intracellular vesicles, these receptors are known to translocate to the nucleus after ligand-induced activation where they appear to control transcriptional events relevant for cell proliferation and other functions (77-79). Although it is well established that ErbB4 is proteolytically processed before nuclear translocation and only the cytosolic segment moves to the nucleus, the full-length EGFR has been proposed to undergo nuclear translocation by a not fully understood mechanism (80). This has opened a strong controversy because it was argued that the experimental evidence for its location in the nucleoplasm was not as strong as suggested (81). Most significantly, it is not clear how the full-length receptor harboring a hydrophobic transmembrane segment undergoes its passage through a nuclear pore. Because the endoplasmic reticulum and the nuclear membrane form a network this could result in the 
misidentification of the compartment where the full-length receptor is indeed located.

\section{Targeting ErbB receptors in cancer}

Overexpression and/or the occurrence of truncated, site-mutated or segment-deleted hyperactive forms of EGFR and ErbB2 are common findings in many solid tumors in humans. These aberrant receptors significantly contribute to the oncogenic process and they have been studied in great detail (82-92). Additionally, oncogenic mutations are also found in a variety of proteins involved in the downstream signaling pathways of the ErbB receptors, as for example in those of the EGFR (93).

Consequently, targeting overexpressed and/or aberrant hyperactive ErbB receptors in anaplastic cells could be a valid therapeutic approach against cancer. In this context, a variety of EGFR and ErbB2 inhibitors have been developed, some of which are under test in clinical trials or are currently used in the clinic. These agents fall into two major categories: tyrosine kinase antagonists and inhibitory antibodies. Small molecules that bind to the tyrosine kinase domain of the receptor inhibiting its intrinsic tyrosine kinase activity form the first group. These compounds may specifically act on a single type of ErbB receptor, may have dual action inhibiting two receptor types (for example EGFR and ErbB2), or may have anti-panErbB activity (94-100). Some of these compounds were identified from a database of traditional medicinal plants by virtually screening their potential inhibitory action on the tyrosine kinase activity of the EGFR (101). The second category of inhibitors includes chimeric, humanized or human monoclonal antibodies targeting the EGFR or ErbB2 (98, 102-107). Emerging techniques such as those using the minimum antigen-recognizing segment of the immunoglobulin against the receptor and/or fusing cytotoxic effector molecules - for example a toxin or an RNase - to a small segment of the anti-ErbB immunoglobulin have been developed to increase the efficacy of these immunodrugs $(104,108,109)$.

As is common with other chemotherapeutic compounds, the use of anti-ErbB receptor agents may have important drawbacks that diminish or totally prevent their efficacy. This could be due to the occurrence of primary resistance of the tumor cells because of the expression of mutant receptors insensitive to the drug; or the establishment of acquired resistance induced by a variety of mechanisms including the appearance of secondary mutations (110-113). Another important problem when dispensing these antibodies to patients is the appearance of systemic or organ-selective toxic effects, for example cardiotoxicity $(114,115)$.

In addition to anti-ErbB receptor drugs targeting either the tyrosine kinase domain or the extracellular region of the receptor preventing ligand binding, activation, internalization, trafficking and/or signaling, there are other important functional sites in these receptors that could be targeted to inhibit their activity. An emerging target site of interest could be the CaM$\mathrm{BD}$ located at the cytosolic JM region of the receptor, as we will describe in the next section.

\section{Targeting the calmodulin-binding domain of the EGFR}

The proximal segment of the cytosolic JM region of the human EGFR (residues 645-663, coded by exon 17), comprising the CaM-BD (residues 645660) plays an important role in the functionality of the receptor, as its impairment results in the loss of most of its intrinsic tyrosine kinase activity without affecting ligand binding. This has been demonstrated either by deletion of this region (69, 116); substitution of critical positively-charged amino acids using site-directed mutagenesis, as for example replacing several arginine/lysine by neutral asparagine or alanine $(73,116,117)$; or replacing the JM (amino acids 650-680) with an unstructured (GGS) 10 sequence (118). The R646 and R647 residues in the proximal part of the cytosolic JM region plus additional residues in the distal JM segment (residues 664-682, coded by exon 18) appear to be most relevant to preserve EGFR activity (117). The importance of the JM region for the activity of the receptor appears to rest in its participation in helping to form an asymmetric dimer involving two apposed tyrosine kinase domains stabilizing the dimer upon ligand binding $(117,119)$. A mutation $(\mathrm{V} 665 \mathrm{M})$ in the distal part of the cytosolic JM region has been shown to constitutively activate the EGFR in human non-small cell lung cancer (NSCLC) (117). However, two small-scale screenings for potential mutations in the JM of the four ErbB receptors gave negative results in a series of 200 human NSCLC samples (120) and 86/89 human astrocytic glioma samples $(87,121)$, suggesting that perhaps mutations in the JM segment are rare as it is required for receptor activity.

Targeting the cytosolic JM region of the EGFR, where the CaM-BD is located, could be an efficient new strategy to inhibit the overexpressed and/or constitutively active mutant receptor present 
in many tumor cells. Some exciting results have recently been obtained in this context. Thus, it has been demonstrated that a peptide corresponding to the proximal part of the cytosolic JM region (residues 645-662), tagged with a segment corresponding to the transactivation of transcription (Tat) sequence of HIV to allow its entry in the cell, induces non-apoptotic cell death after several hours of treatment, and caspase-3mediated apoptosis after longer exposure in a variety of tumor cells expressing EGFR, but having reduced action on non-tumor cells and tumor cells not expressing EGFR (122). This peptide also decreases tumor growth in vivo, and increases the survival rate of experimental animals implanted with the tumor cells (122). The mechanism of action of the peptide appears mediated by its binds to the EGFR preventing receptor dimerization and favoring its downregulation (122).

A peptide corresponding to the sequence R651-L658 of the EGFR in which threonine 654 has been substituted by a cysteine (RKRCLRRL, abbreviated T654C) (see Figure 1b) has been shown to inhibit PKC in an irreversible fashion because forms a disulfide bridge with a cysteine located in the catalytic site of the kinase (123). PKC is known to phosphorylate the EGFR at T654 (124), and to test whether this peptide was able as well to inhibit ligand-dependent activation of the EGFR in intact cells it was tagged with the membrane-permeable carrier sequence AAVALLPAVLLALAP (see Figure 1b). This sequence comprises the hydrophobic (h)-region of the signal sequence of the Kaposi fibroblast growth factor and is unlikely to produce by itself toxic effects, as it is a physiological signal peptide facilitating protein secretion (125). Moreover, this specific carrier sequence has been previously used to introduce several effector peptides inside living cells in order to disrupt the functionality of a variety of signaling pathways $(126,127)$.

We have demonstrated in murine EGFR-T17 fibroblasts overexpressing the EGFR that the T654C peptide tagged with the cell-permeable sequence inhibits both the ligand-dependent phosphorylation (activation) of the EGFR (see Figure 1c), and cell proliferation as determined by [methyl- ${ }^{3} \mathrm{H}$ ] thymidine incorporation into DNA (see Figure 1d), in contrast to the short T654C peptide lacking the carrier sequence and therefore unable to enter into the cells, at least with significant efficiency. The treatment of cells with the long T654C cell-permeable peptide eventually leads to cell death (Ruano and Villalobo, unpublished). The inhibitory effect of this peptide was also demonstrated in human epidermoid carcinoma A431 cells that also overexpress the EGFR (Ruano and Villalobo, unpublished). It is likely that the overexpression of the EGFR might facilitate the drastic inhibitory effects observed in these cells. The long T654C cell-permeable peptide might have a complex mechanism of action since it is an inhibitor of PKC (123), and it has not been tested if the cysteine prevents $\mathrm{CaM}$ binding. Nevertheless, our results are in agreement with those recently published using a distinct, though overlapping, peptide that binds to the EGFR preventing dimerization (122). Because of their related sequences, it is likely that both peptides have EGFR-interacting capacity.

This demonstrates that peptides based on the CaM-BD of the EGFR could be potential therapeutic agents against tumors expressing this receptor. Similarly, it could be important to explore in future studies the potential inhibitory action of cell-permeable peptides corresponding to the two CaM-BDs of ErbB2 in tumor cells expressing this receptor, as for example and most significant in some subtypes of human breast cancer.

Interestingly, the proposed NLS of the EGFR (128) overlaps with its CaM-BD (77) (see Figure 1a). This underscores the potential implication of $\mathrm{CaM}$ in the regulation of the nuclear translocation of the EGFR, even if only the cytosolic portion but not the full-length receptor moves to the nucleus. Nuclear EGFR associates to the catalytic subunit of DNA-PK inducing DNA repair. Mutation or deletion of the overlapping CaM-BD/NLS, however, prevents the nuclear localization of the EGFR and its association to DNA-PK, thus dampening the activity of this enzyme and subsequently reducing the DNA repairing activity (129). This may decrease the efficiency to the treatment of patients undergoing chemotherapy or ionizing radiation, highlighting the potential usefulness of targeting this region of the EGFR to additionally reduce the occurrence of resistance to these treatments in cancer patients.

\section{Grb7 AND CALMODULIN}

Our laboratory has also described the presence of a CaM-BD in the proximal region of the $\mathrm{PH}$ domain of human Grb7 comprising the sequence ${ }^{243}$ RKLWKRFFCFLRRS ${ }^{256}$ that is predicted to form a basic amphipathic $\alpha$-helix (see Figure 2a) (41). Sequence homology analysis shows that the CaM-BD of human, rat and mouse Grb7 are 


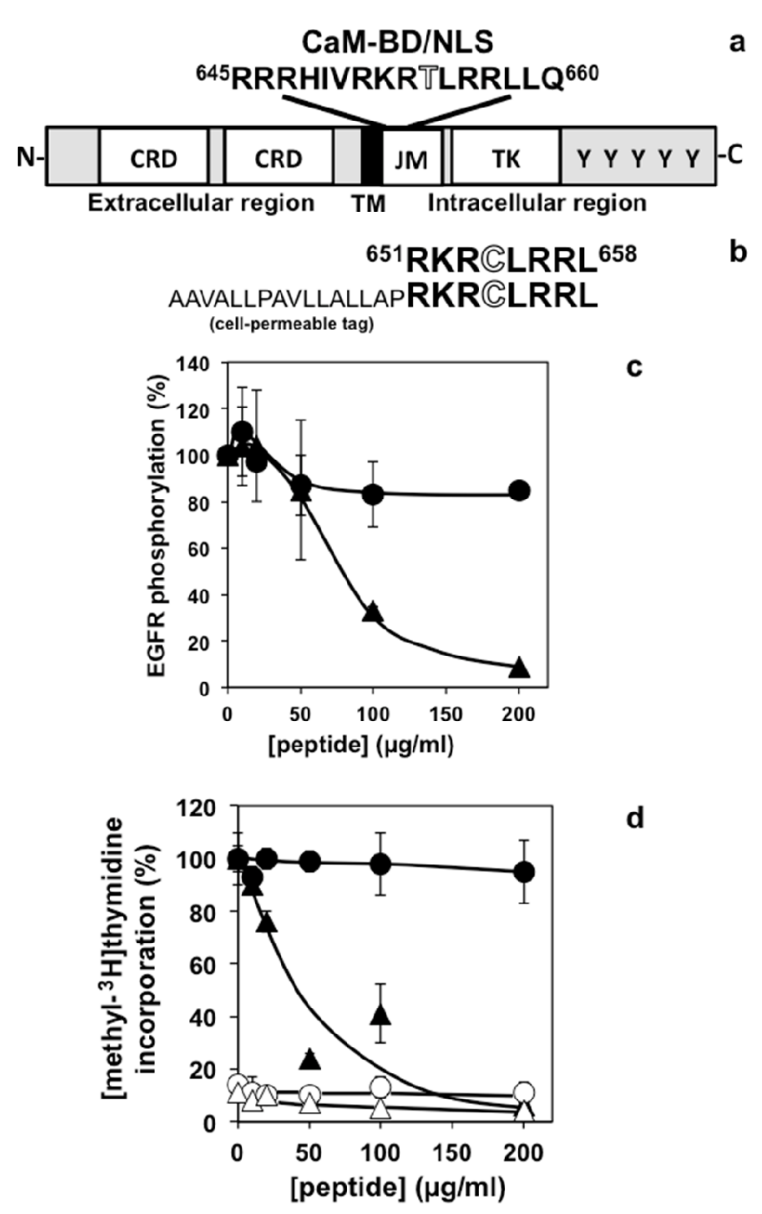

Figure. 1. Inhibitory effects of a modified cellpermeable EGFR peptide. a) Schematic representation of the EGFR structure showing the extracellular region containing two cysteine-rich domains (CRD); the transmembrane segment (TM); and the intracellular region comprising the cytosolic juxtamembrane segment (JM), the tyrosine kinase domain (TK), and the C-terminal tail with auto-phosphorylatable tyrosine residues (Y). The calmodulin-binding domain (CaM$\mathrm{BD}$ ), which overlaps the nuclear localization sequence (NLS), located in the proximal region of the cytosolic JM segment is indicated. The PKC-phosphorylatable residue T654 is highlighted. b) Amino acid sequences of the short and long (cell-permeable) T654C peptides. The N-terminal hydrophobic tag (plain font) and the substituted residue C654 are highlighted. c) The plot presents the mean \pm range $(n=2)$ ligand-dependent phosphorylation of the EGFR in the presence of increasing concentrations of the short (circles) and long cell-permeable (triangles) peptides added to EGFR-T17 fibroblasts. d) The plot presents the mean $\pm \operatorname{SEM}(n=4)$ incorporation of $\left[\right.$ methyl- $\left.{ }^{3} \mathrm{H}\right]$ thymidine into DNA of EGFR-T17 fibroblasts in the absence (open symbols) and presence (filled symbols) of serum at increasing concentrations of the short (circles) and long cellpermeable (triangles) peptides (Ruano and Villalobo, unpublished). identical, and that this region is highly conserved in Grb10 and Grb14 (23, 41). The truncated splice variant Grb7V lacking the C-terminal SH2 domain and expressed in certain adenocarcinomas (29) also maintains intact its CaM-BD $(23,41)$.

We have demonstrated that $\mathrm{CaM}$ binds to Grb7 and $\mathrm{Grb} 7 \mathrm{~V}$ in a $\mathrm{Ca}^{2+}$-dependent manner in vitro and in living cells, and that the deletion mutants Grb7 $\Delta$ and Grb7V $\Delta$ lacking the sequence corresponding to the proposed CaM-BD result in the near full loss of their capacity to bind $\mathrm{CaM}$ (41). Grb7 $\Delta$ and Grb7V $\Delta$ have less ability to bind to membranes although they retain in part their capacity to bind to phosphoinositides (41). Moreover, the CaM antagonist W-7 - but not the CaMK-II inhibitor KN93 - prevents the translocation of Grb7 from the membrane to the cytosol upon activation of ErbB2 induced by heregulin $\beta 1$ in live cells, and a cell-permeable $\mathrm{CaM}$ sequestering peptide corresponding to the CaM-BD of MLCK decreases the association of Grb7 to cell membranes (41). Also, we have demonstrated that wild type Grb7 is translocated to the nucleus and that W-7 enhances this process, while Grb7 $\Delta$ lacks this capacity (130). As the NLS and CaM-BD of Grb7 share superimposed sequences (see Figure 2a), our results suggest that $\mathrm{CaM}$ binding to Grb7 could occlude its NLS preventing in this manner the translocation of the protein to the nucleus and downstream signaling events occurring at this location (130).

\section{Targeting Grb7 in cancer}

Grb7 has been proposed to be a promising new target for anti-cancer therapy, as disrupting its functionality could inhibit the migratory capacity of tumor cells, their invasiveness and metastatic potential, and/or cell proliferation. As an example, it has been proposed that targeting the Grb7/ERK pathway and the downstream transcription factor FOXM1 could be a useful strategy to inhibit the growth, cell migratory capacity and invasiveness of ovarian tumor cells, as demonstrated in vitro and in vivo (131).

The SH2 domain of Grb7 has been suggested as a key target to inhibit this adaptor protein, most prominently using mimetic peptides (132). The cyclic structure of a small synthetic nonphosphorylated peptide containing an YXN motif, where $\mathrm{X}$ represents any amino acid, was shown to bind to the SH2 domain of Grb7 disrupting the interaction between Grb7 and ErbB receptors (133), and Grb7 and FAK (134). The peptide denoted G7-18NATE, with the sequence 
WFEGYDNTFPC, that cyclizes forming a thioether bond, inhibits the proliferation of a series of human breast cancer cells expressing Grb7 when tagged with a cell-permeable carrier sequence (37), and attenuates as well cell migration and the development of peritoneal metastasis from a primary pancreatic tumor in a mouse model (134). Furthermore, the G7-18NATE peptide presents a synergistic effect with other classical chemotherapeutic agents, such as the DNAintercalating agent Doxorubicin, and the monoclonal antibody against ErbB2 denoted Trastuzumab (Herceptin) (37).

Moreover, a series of eleven benzopyrazine derivatives (135) and nine phenylbenzamine derivatives (136) targeting the SH2 domain of Grb7 have also been tested as potential antagonists of this adaptor protein. The leading compounds in the two series inhibited in culture the viability of a human breast cancer cell line overexpressing Grb7 $(135,136)$. These compounds were most effective at concentrations in the medium $\mu$ molar range $(135,136)$. Nevertheless, their efficacy, if any, against tumors in vivo remains to be tested.
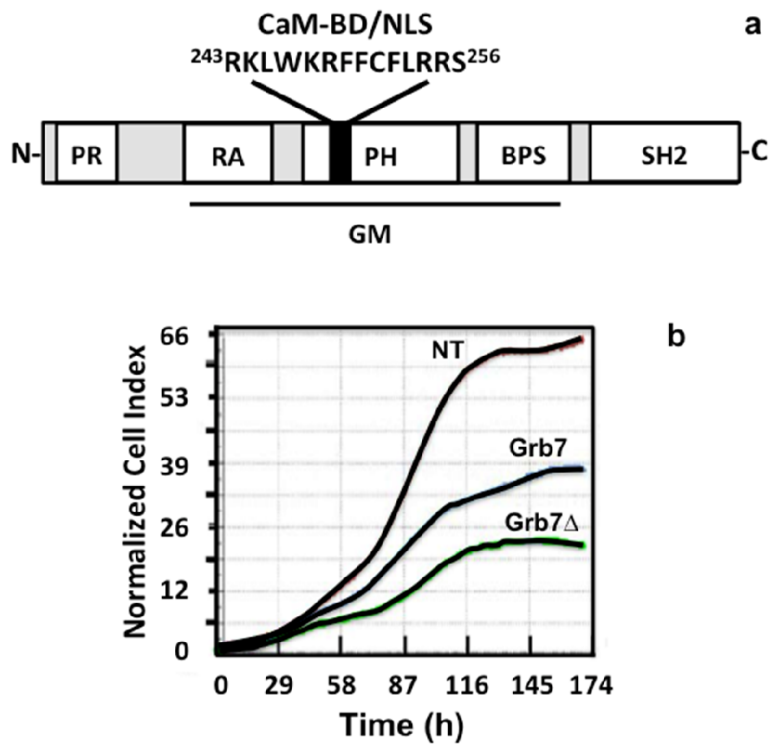

Figure. 2. Deletion of the CaM-BD of Grb7 decreases cell proliferation. a) Schematic representation of the Grb7 structure showing the PR, RA, PH, BPS and SH2 domains and highlighting the central GM region (see text for details). The calmodulin-binding domain (CaM$\mathrm{BD}$ ), overlapping the nuclear localization sequence (NLS), located in the proximal region of the $\mathrm{PH}$ domain is indicated. b) The plot shows the proliferation of nontransfected (NT) and stably transfected HEK-293 cells expressing Grb7 or Grb7 $\Delta$ growing in the presence of serum and monitored in an xCELLigence RTCA system (García-Palmero and Villalobo, unpublished).

\section{Targeting the calmodulin-binding domain of Grb7}

To the best of our knowledge there is no information available on inhibitory compounds specifically targeting the CaM-BD of Grb7. However, this region of the protein could be a potential target for therapeutic intervention. This is based on interesting inhibitory effects observed in cells expressing the deletion mutant EYFP-Grb7 $\Delta$ that lacks the CaM-BD, as compared to cells expressing EYFP-Grb7 (wild type) or EYFP alone. Thus, we have shown that rat glioma C6 cells expressing the mutant protein presented lower proliferation rate and diminished migratory capacity than the control cells (38). As an additional example, the inhibitory action of Grb7 $\Delta$ on the proliferation of HEK-293 cells, as compared to wild type Grb7 or non-transfected cells is documented in Figure 2b. Although overexpression of Grb7 in tumors induces cell growth, the observed inhibitory effect of wild type Grb7 as compared to non-expressing cells (Figure $2 b$ and Ref. 38), suggests that Grb7 may have a biphasic action when controlling cell proliferation. Expression of Grb7 $\Delta$ also inhibits the migration of HEK-293 cells as compared to control cells (García-Palmero and Villalobo, unpublished results). Most relevant, these inhibitory effects were also observed in vivo measuring the growth of brain tumors derived from implanted C6 cells expressing the wild type and mutant proteins as determined by MRI (38).

Conditioned media from cells expressing Grb7 $\Delta$ or Grb7V $\Delta$ also present strong antiangiogenic activity, as compared to media from cells expressing their respective wild type counterparts, when tested on human vascular endothelial cells forming tubular structures in an in vitro assay system (41). The anti-angiogenic effect of Grb7 $\Delta$ was also corroborated in vivo, as tumors derived from glioma C6 cells stably expressing the chimera EYFP-Grb7 $\Delta$ and stereotaxically implanted in rat brain presented lower vascular performance and were less angiogenic that tumors derived from C6 cells stably expressing EYFPGrb7 or EYFP alone, as determined by MRI perfusion techniques (38). This opens the possibility that targeting the CaM-BD of Grb7 with selective cell-permeable peptides or other compounds in tumors naturally expressing this adaptor protein could be an additional strategy to inhibit tumor-associated angiogenesis and tumor growth. 


\section{FUTURE PERSPECTIVES}

Many studies mostly performed in vitro point to a potential benefit of treating cancers with $\mathrm{CaM}$ antagonists. However, the therapeutic benefit of this strategy in patients has yet to be demonstrated because of the noxious side effects expected, even using sub-optimal doses. An alternative strategy that should be explored is targeting the site(s) of action of CaM in specific CaM-dependent systems that are upregulated and/or overexpressed in tumor cells, as we have proposed in this review with the CaM-BD of ErbB receptors and Grb7. Combinatory therapy targeting several systems at once could be a way to minimize the appearance of resistance to the drugs. Efforts are needed to discover specific biomarkers for the selective delivery of the intended drugs to the tumor, particularly targeting the tumor stem-cells, avoiding as much as possible the normal tissues.

Acknowledgements: The work in the authors laboratory was funded in part by grants (to AV) from the Secretaria de Estado de Investigación Desarrollo e Innovación - SEIDEI (SAF201123494), the Consejería de Educación de la Comunidad de Madrid (S2010/BMD-2349), the Agencia Española de Cooperación Internacional para el Desarrollo - AECID (AP/040803/11), and the European Commission (contract PITN-GA2011-289033). IG-P, SRS and KJ were respectively supported by a fellowship from the Ministerio de Educación Cultura y Deporte, a Madame Curie contract from the European Commission, and a grant from the $A E C I D$. We thank Dr. Catherine A. O'Brian (University of Texas - MD Anderson Cancer Center) for generously donating the peptides.

Abbreviations: 5'-UTR, 5'-untranslated region; CaM, calmodulin; CaM-BD, CaM-binding domain; CaMK-II, CaM-dependent protein kinase II; c-Cbl, cellular Casitas B-lineage lymphoma proto-oncogene; DNA-PK, DNA-dependent protein kinase; EGFR, epidermal growth factor receptor; ErbB1/2/3/4, erythroblastic leukemia viral oncogene homologues 1 to 4; EYFP, enhanced yellow fluorescence protein; FAK, focal adhesion kinase; FOXM1, forkhead box M1; Grb7/10/14, growth factor receptor bound proteins 7/10/14; HER1/2/3/4, human EGFR 1 to 4; HIV, human immunodeficiency virus; JM, juxtamembrane; KN-93, 2-[N-(2-hydroxyethyl)]$N$-(4-methoxybenzenesulfonyl)] amino- $N$-(4chlorocinnamyl)- $N$-methylbenzylamine; MLCK, myosin light-chain kinase; MRI, magnetic resonance imaging; NLS, nuclear localization sequence; $\mathrm{PH}$, pleckstrin homology; $\mathrm{PKC}$, protein kinase C; PR, proline-rich; PTB, phospho-tyrosinebinding; RA, Ras-associating; SH2, Src homology 2; RTK, receptor tyrosine kinase; shRNA, small hairpin RNA; siRNA, small interfering RNA; W-7, $N$-(6-aminohexyl)-5-chloro-1-

naphthalenesulfonamide.

\section{REFERENCES}

1. Downward J, Parker P, Waterfield MD. Autophosphorylation sites on the epidermal growth factor receptor. Nature, 1984; 311:483485.

2. Carpenter G. Receptors for epidermal growth factor and other polypeptide mitogens. Annu Rev Biochem, 1987; 56:881-914.

3. Margolis BL, Lax I, Kris R, Dombalagian M, Honegger AM, Howk R, Givol D, Ullrich A, Schlessinger J. All autophosphorylation sites of epidermal growth factor (EGF) receptor and HER2/neu are located in their carboxyl-terminal tails: identification of a novel site in EGF receptor. J Biol Chem, 1989; 264:10667-10671.

4. Jorissen RN, Walker F, Pouliot N, Garrett TPJ, Ward CW, Burgess AW. Epidermal growth factor receptor: mechanisms of activation and signalling. Exp Cell Res, 2003; 284:31-53.

5. Alroy I, Yarden Y. The ErbB signaling network in embryogenesis and oncogenesis: signal diversification through combinatorial ligandreceptor interactions. FEBS Lett, 1997; 410:83-86.

6. Harris RC, Chung E, Coffey RJ. EGF receptor ligands. Exp Cell Res, 2003; 284:2-13.

7. Zhang X, Gureasko J, Shen K, Cole PA, Kuriyan J. An allosteric mechanism for activation of the kinase domain of epidermal growth factor receptor. Cell, 2006; 125:1137-1149.

8. Citri A, Skaria KB, Yarden Y. The deaf and the dumb: the biology of ErbB-2 and ErbB-3. Exp Cell Res, 2003; 284:54-65.

9. Citri A, Yarden Y. EGF-ERBB signalling: towards the systems level. Nat Rev Mol Cell Biol, 2006; 7:505-515.

10. Warren CM, Landgraf R. Signaling through ERBB receptors: multiple layers of diversity and control. Cell Signal, 2006; 18:923-933.

11. Alwan HAJ, van Zoelen EJJ, van Leeuwen JEM. Ligand-induced lysosomal epidermal growth factor receptor (EGFR) degradation is preceded by proteasome-dependent EGFR de-ubiquitination. J Biol Chem, 2003; 278:35781-35790.

12. Wiley HS. Trafficking of the ErbB receptors and its influence on signaling. Exp Cell Res, 2003; 284:78-88.

13. Kirisits A, Pils D, Krainer M. Epidermal growth factor receptor degradation: an alternative view of 
oncogenic pathways. Int $\mathrm{J}$ Biochem Cell Biol, 2007; 39:2173-2182.

14. Cohen BD, Siegall CB, Bacus S, Foy L, Green JM, Hellström I, Hellström KE, Fell HP. Role of epidermal growth factor receptor family members in growth and differentiation of breast carcinoma. Biochem Soc Symp, 1998; 63:199-210.

15. Linggi B, Carpenter G. ErbB receptors: new insights on mechanisms and biology. Trends Cell Biol, 2006; 16:649-656.

16. Reinehr R, Häussinger D. Epidermal growth factor receptor signaling in liver cell proliferation and apoptosis. Biol Chem, 2009; 390:1033-1037.

17. Feigin ME, Muthuswamy SK. ErbB receptors and cell polarity: new pathways and paradigms for understanding cell migration and invasion. Exp Cell Res, 2009; 315:707-716.

18. Hynes NE, MacDonald G. ErbB receptors and signaling pathways in cancer. Curr Opi Cell Biol, 2009; 21:177-184.

19. Rush JS, Quinalty LM, Engelman L, Sherry DM, Ceresa BP. Endosomal accumulation of the activated epidermal growth factor receptor (EGFR) induces apoptosis. J Biol Chem, 2012; 287:712-722.

20. Margolis B. The GRB family of $\mathrm{SH} 2$ domain proteins. Prog Biophys Mol Biol, 1994; 62:223244.

21. Daly RJ. The Grb7 family of signalling proteins. Cell Signal, 1998; 10:613-618.

22. Han DC, Shen T-L, Guan J-L. The Grb7 family proteins: structure, interactions with other signaling molecules and potential cellular functions. Oncogene, 2001; 20:6315-6321.

23. Villalobo A, Li H, Sánchez-Torres J. The Grb7 protein family. Curr Top Biochem Res, 2003; 5:105-114.

24. Lucas-Fernández E, García-Palmero I, Villalobo A. Genomic organization and control of the Grb7 gene family. Curr Genomics, 2008; 9:60-68.

25. Manser J, Wood WB. Mutations affecting embryonic cell migrations in Caenorhabditis elegans. Dev Genet, 1990; 11:49-64.

26. Manser J, Roonprapunt C, Margolis B. C. elegans cell migration gene mig-10 shares similarities with a family of $\mathrm{SH} 2$ domain proteins and acts cell nonautonomously in excretory canal development. Dev Biol, 1997; 184:150-164.

27. Han DC, Guan J-L. Association of focal adhesion kinase with Grb7 and its role in cell migration. J Biol Chem, 1999; 274:24425-24430.

28. Han DC, Shen T-L, Miao H, Wang B, Guan J-L. EphB1 associates with Grb7 and regulates cell migration. J Biol Chem, 2002; 277:45655-45661.

29. Tanaka S, Mori M, Akiyoshi T, Tanaka Y, Mafune K, Wands JR, Sugimachi K. A novel variant of human Grb7 is associated with invasive esophaheal carcinoma. J Clin Invest, 1998; 102:821-827.

30. Tanaka S, Sugimachi K, Kawaguchi H, Saeki H,
Ohno S, Wands JR, Sugimachi K. Grb7 signal transduction protein mediates metastatic progression of esophageal carcinoma. J Cell Physiol, 2000; 183:411-415.

31. Wang Y, Chan DW, Liu VWS, Chu PM, Ngan HYS. Differential functions of growth factor receptor-bound protein 7 (GRB7) and its variant GRB7v in ovarian carcinogenesis. Clin Cancer Res, 2010; 16:2529-2539.

32. Ramsey B, Bai T, Newell AH, Troxell M, Park B, Olson S, Keenan E, Luoh S-W. GRB7 protein over-expression and clinical outcome in breast cancer. Breast Cancer Res Treat, 2011; 127:659669.

33. Giricz O, Calvo V, Pero SC, Krag DN, Sparano JA, Kenny PA. GRB7 is required for triplenegative breast cancer cell invasion and survival. Breast Cancer Res Treat, 2012; 133:607-615.

34. Chu P-Y, Huang L-Y, Hsu C-H, Liang C-C, Guan J-L, Hung T-H, Shen T-L. Tyrosine phosphorylation of growth factor receptor-bound protein-7 by focal adhesion kinase in the regulation of cell migration, proliferation, and tumorigenesis. J Biol Chem, 2009; 284:2021520226.

35. Chu P-Y, Li T-K, Ding S-T, Lai I-R Shen T-L. EGF-induced Grb7 recruits and promotes Ras activity essential for the tumorigenicity of Sk-Br3 breast cancer cells. J Biol Chem, 2010; 285:29279-29285.

36. Kao J, Pollack J-R. RNA interference-based functional dissection of the $17 \mathrm{q} 12$ amplicon in breast cancer reveals contribution of coamplified genes. Genes Chrom Cancer, 2006; 45:761-769.

37. Pero SC, Shukla GS, Cookson MM, Flemer S Jr, Krag DN. Combination treatment with Grb7 peptide and Doxorubicin or Trastuzumab (Herceptin) results in cooperative cell growth inhibition in breast cancer cells. Br J Cancer, 2007; 96:1520-1525.

38. García-Palmero I, López-Larrubia P, Cerdán S, Villalobo A. Nuclear magnetic resonance imaging of tumour growth and neovasculature performance in vivo reveals Grb7 as a novel antiangiogenic target. NMR Biomed, 2013; doi: 10.1002/nbm. 2918.

39. Tsai N-P, Bi J, Wei L-N. The adaptor Grb7 links netrin-1 signaling to regulation of mRNA translation. EMBO J, 2007; 26:1522-1531.

40. Tsai N-P, Ho P-C, Wei L-N. Regulation of stress granule dynamics by Grb7 and FAK signaling pathway. EMBO J, 2008; 27:715-726.

41. Li H, Sánchez-Torres J, del Carpio AF, NogalesGonzález A, Molina-Ortiz P, Moreno MJ, Török $\mathrm{K}$, Villalobo A. The adaptor Grb7 is a new calmodulin-binding protein: functional implications of the interaction of calmodulin with Grb7. Oncogene, 2005; 24:4206-4219.

42. Klee CB, Crouch TH, Richman PG. Calmodulin. Ann Rev Biochem, 1980; 49:489-515. 
43. Chin D, Means AR. Calmodulin: a prototypical calcium sensor. Trends Cell Biol, 2000; 10:322328.

44. Persechini A, Cronk B. The relationship between the free concentrations of $\mathrm{Ca}^{2+}$ and $\mathrm{Ca}^{2+}$ calmodulin in intact cells. J Biol Chem, 1999; 274:6827-6830.

45. Dagher R, Peng S, Gioria S, Fève M, Zeniou M, Zimmermann M, Pigault C, Haiech J, Kilhoffer M-C. A general strategy to characterize calmodulin-calcium complexes in CaM-target recognition: DAPK and EGFR calmodulin binding domains interact with different calmodulincalcium complexes. Biochim Biophys Acta, 2011; 1813:1059-1067.

46. Shifman JM, Choi MH, Mihalas S, Mayo SL, Kennedy $\mathrm{MB}$. $\mathrm{Ca}^{2+} /$ calmodulin-dependent protein kinase II (CaMKII) is activated by calmodulin with two bound calciums. Proc Natl Acad Sci USA, 2006; 103:13968-13973.

47. Jurado LA, Chockalingam PS, Jarrett HW. Apocalmodulin. Physiol Rev, 1999; 79:661-682.

48. O’Neil KT, DeGrado WF. How calmodulin binds its targets: sequence independent recognition of amphiphilic $\square$-helices. Trends Biochem Sci, 1990; 15:59-64.

49. Rhoads AR, Friedberg F. Sequence motifs for calmodulin recognition. FASEB J, 1997; 11:331340 .

50. Hoeflich KP, Ikura M. Calmodulin in action: diversity in target recognition and activation mechanisms. Cell, 2002; 108:739-742.

51. Wei JW, Hickie RZ, Klaassen DJ. Inhibition of human breast cancer colony formation by anticalmodulin agents: trifluoperazine, W-7, and W-13. Cancer Chemother Pharmacol, 1983; 11:86-90.

52. Hait WN, Lazo JS. Calmodulin: a potential target for cancer chemotherapeutic agents. J Clin Oncol, 1986; 4:994-1012.

53. Orosz F, Horváth I, Ovádi J. New anti-mitotic drugs with distinct anti-calmodulin activity. Mini Rev Med Chem, 2006; 6:1145-1157.

54. Mayur YC, Jagadeesh S, Thimmaiah KN. Targeting calmodulin in reversing multi drug resistance in cancer cells. Mini Rev Med Chem, 2006; 6:1383-1389.

55. Weiss B, Prozialeck WC, Wallace TL. Interaction of drugs with calmodulin: biochemical, pharmacological and clinical implications. Biochem Pharmacol, 1982; 31:2217-2226.

56. Roufogalis BD, Minocherhomjee AM, Al-Jobore A. Pharmacological antagonism of calmodulin. Can J Biochem Cell Biol, 1983; 61:927-933.

57. Walsh MP. Calmodulin: structure-function relations and inhibitors. Rev Clin Basic Pharm, 1985; 5:35-69.

58. Veigl ML, Klevit RE, Sedwick WD. The use and limitations of calmodulin antagonists. Pharmacol Ther, 1989; 44:181-239.
59. Hidaka H, Ishikawa T. Molecular pharmacology of calmodulin pathways in the cell functions. Cell Calcium, 1992; 13:465-472.

60. Martínez-Luis S, Pérez-Vásquez A, Mata R. Natural products with calmodulin inhibitor properties. Phytochemistry, 2007; 68:1882-1903.

61. Takuwa N, Zhow W, Takuwa Y. Calcium, calmodulin and cell cycle progression. Cell Signal, 1995; 7:93-104.

62. Sánchez-González $\mathrm{P}$, Jellali K, Villalobo A. Calmodulin-mediated regulation of the epidermal growth factor receptor. FEBS J, 2010; 277:327342.

63. San José E, Benguría A, Geller P, Villalobo A. Calmodulin inhibits the epidermal growth factor receptor tyrosine kinase. J Biol Chem, 1992; 267:15237-15245.

64. Martín-Nieto J, Villalobo A. The human epidermal growth factor receptor contains a juxtamembrane calmodulin-binding site. Biochemistry, 1998; 37:227-236.

65. Aifa S, Johansen K, Nilsson UK, Liedberg B, Lundström I, Svensson SPS. Interactions between the juxtamembrane domain of the EGFR and calmodulin measured by surface plasmon resonance. Cell Signal, 2002; 14:1005-1013.

66. $\mathrm{Li} \mathrm{H}$, Villalobo A. Evidence for the direct interaction between calmodulin and the human epidermal growth factor receptor. Biochem J, 2002; 362:499-505.

67. Li H, Ruano MJ, Villalobo A. Endogenous calmodulin interacts with the epidermal growth factor receptor in living cells. FEBS Lett, 2004; 559:175-180.

68. McLaughlin S, Smith SO, Hayman MJ, Murray D. An electrostatic engine model for autoinhibition and activation of the epidermal growth factor receptor (EGFR/ErbB) family. J Gen Physiol, 2005; 126:41-53.

69. Aifa S, Aydin J, Nordvall G, Lundström I, Svensson SPS, Hermanson O. A basic peptide within the juxtamembrane region is required for EGF receptor dimerization. Exp Cell Res, 2005; 302:108-114.

70. Sato T, Pallavi P, Golebiewska U, McLaughlin S, Smith SO. Structure of the membrane reconstituted transmembrane-juxtamembrane peptide EGFR(622-660) and its interaction with $\mathrm{Ca}^{2+} /$ calmodulin. Biochemistry, 2006; 45:1270412714.

71. Sengupta P, Ruano MJ, Tebar F, Golebiewska U, Zaitseva I, Enrich C, McLaughlin S, Villalobo A. Membrane-permeable calmodulin inhibitors (e.g., $\mathrm{W}-7 / \mathrm{W}-13$ ) bind to membranes, changing the electrostatic surface potential: dual effect of W-13 on EGFR activation. J Biol Chem, 2007; 282:8474-8486.

72. Panina S, Stephan A, La Cour JM, Jacobsen K, Kallerup LK, Bumbuleviciute R, Knudsen KVK, Sánchez-González P, Villalobo A, Olesen UH, 
Berchtold MW. Significance of calcium binding, tyrosine phosphorylation, and lysine trimethylation for the essential function of calmodulin in vertebrate cells analyzed in a novel gene replacement system. J Biol Chem, 2012; 287:18173-18181.

73. Li H, Panina S, Kaur A, Ruano MJ, SánchezGonzález P, La Cour JM, Stephan A, Olesen UH, Berchtold MW, Villalobo A. Regulation of the ligand-dependent activation of the epidermal growth factor receptor by calmodulin. J Biol Chem, 2012; 287:3273-3281.

74. Martín-Nieto J, Cusidó-Hita DM, Li H, Benguría A, Villalobo A, Regulation of ErbB receptors by calmodulin, in Pandalai SG (ed), Recent Research Developments in Biochemistry vol. 3, Research Signpost, Trivandrum, pp. 41-58, 2002.

75. Li H, Sánchez-Torres J, del Carpio A, Salas V, Villalobo A. The ErbB2/Neu/HER2 receptor is a new calmodulin-binding protein. Biochem J, 2004; 381:257-266.

76. White CD, Li Z, Sacks DB. Calmodulin binds HER2 and modulates HER2 signaling. Biochim Biophys Acta, 2011; 1813:1074-1082.

77. Villalobo A, García-Andrés C, Molina-Ortiz P. Translocation of ErbB receptors into the nucleus. Rev Oncol, 2003; 5:381-389.

78. Brand TM, lida M, Li C, Wheeler DL. The nuclear epidermal growth factor receptor signaling network and its role in cancer. Discov Med, 2011; 12:419-432.

79. Wang Y-N, Hung M-C. Nuclear functions and subcellular trafficking mechanisms of the epidermal growth factor receptor family. Cell Biosci, 2012; 2:13.

80. Lin S-Y, Makino K, Xia WY, Matin A, Wen Y, Kwong KY, Bourguignon L, Hung MC. Nuclear localization of EGF receptor and its potential new role as a transcription factor. Nat Cell Biol, 2001; 3:802-808.

81. Schlessinger J, Lemmon MA. Nuclear signaling by receptor tyrosine kinases: the first robin of spring. Cell, 2006; 127:45-48.

82. Kim H, Muller WJ. The role of the epidermal growth factor receptor family in mammary tumorigenesis and metastasis. Exp Cell Res, 1999; 253:78-87.

83. Yu D, Hung MC. Overexpression of ErbB2 in cancer and ErbB2-targeting strategies. Oncogene, 2000; 19:6115-6121.

84. Pedersen MW, Meltorn M, Damstrup L, Poulsen HS. The type III epidermal growth factor receptor mutation: biological significance and potential target for anti-cancer therapy. Ann Oncol, 2001; 12:745-760.

85. Roskoski RJr. The ErbB/HER receptor proteintyrosine kinases and cancer. Biochem Biophys Res Commun, 2004; 319:1-11.

86. Stephens P, Hunter C, Bignell G, Edkins S, Davies H, Teague J, Stevens C, O'Meara S, Smith R,
Parker A, Barthorpe A, Blow M, Brackenbury L, Butler A, Clarke O, Cole J, Dicks E, Dike A, Drozd A, Edwards K, Forbes S, Foster R, Gray K, Greenman C, Halliday K, Hills K, Kosmidou V, Lugg R, Menzies A, Perry J, Petty R, Raine K, Ratford L, Shepherd R, Small A, Stephens Y, Tofts C, Varian J, West S, Widaa S, Yates A, Brasseur F, Cooper CS, Flanagan AM, Knowles M, Leung SY, Louis DN, Looijenga LH, Malkowicz B, Pierotti MA, Teh B, ChenevixTrench G, Weber BL, Yuen ST, Harris G, Goldstraw P, Nicholson AG, Futreal PA, Wooster $\mathrm{R}$, Stratton MR. Lung cancer: intragenic ERBB2 kinase mutations in tumours. Nature, 2004; 431:525-526.

87. Arjona D, Bello MJ, Alonso ME, GonzálezGómez P, Aminoso C, Isla A, de Campos JM, Vaquero J, Gutierrez M, Villalobo A, Rey JA. Molecular analysis of the EGFR gene in astrocytic gliomas: mRNA expression, quantitative-PCR analysis of non homogeneous gene amplification and DNA sequence alterations. Neuropathol Appl Neurobiol, 2005; 31:384-394.

88. Sharma SV, Bell DW, Settleman J, Haber DA. Epidermal growth factor receptor mutations in lung cancer. Nat Rev Cancer, 2007; 7:169-181.

89. Gan HK, Kave AH, Luwor RB. The EGFRvIII variant in glioblastoma multiforme. $\mathrm{J}$ Clin Neurosci, 2009; 16:748-754.

90. Pines G, Köstler WJ, Yarden Y. Oncogenic mutant forms of EGFR: lessons in signal transduction and targets for cancer therapy. FEBS Lett, 2010; 584:2699-2706.

91. Da Cunha Santos G, Shepherd FA, Tsao MS. EGFR mutations and lung cancer. Annu Rev Pathol, 2011; 6:49-69.

92. Arcila ME, Chaft JE, Nafa K, Roy-Chowdhuri S, Lau C, Zaidinski M, Paik PK, Zakowski MF, Kris MG, Ladanyi M. Prevalence, clinicopathologic associations, and molecular spectrum of ERBB2 (HER2) tyrosine kinase mutations in lung adenocarcinomas. Clin Cancer Res, 2012; 18:4910-4918.

93. Grossmann AH, Samowitz WS. Epidermal growth factor receptor pathway mutations and colorectal cancer therapy. Arch Pathol Lab Med, 2011; 135:1278-1282.

94. Anderson NG, Ahmad T. ErbB receptor tyrosine kinase inhibitors as therapeutic agents. Front Biosci, 2002; 7:d1926-d1940.

95. Normanno N, Maiello MR, De Luca A. Epidermal growth factor receptor tyrosine kinase inhibitors (EGFR-TKIs): simple drugs with a complex mechanism of action? J Cell Physiol, 2002; 194:13-19.

96. Normanno N, Maiello MR, Mancino M, De Luca A. Small molecule epidermal growth factor receptor tyrosine kinase inhibitors: an overview. J Chemother, 2004; 16 Supp14:36-40.

97. Ranson M. Epidermal growth factor receptor 
tyrosine kinase inhibitors. Br J Cancer, 2004; 90:2250-2255.

98. Mendelson J, Baselga J. Epidermal growth factor receptor targeting in cancer. Semin Oncol, 2006; 33:369-385.

99. Sequist LV. Second-generation epidermal growth factor receptor tyrosine kinase inhibitors in nonsmall cell lung cancer. Oncologist, 2007; 12:325330 .

100. Jamal-Hanjani M, Spicer J. Epidermal growth factor receptor tyrosine kinase inhibitors in the treatment of epidermal growth factor receptormutant non-small cell lung cancer metastatic to the brain. Clin Cancer Res, 2012; 18:938-944.

101. Sawatdichaikul O, Hannongbua S, Sangma C, Wolschann $\mathrm{P}$, Choowongkomon $\mathrm{K}$. In silico screening of epidermal growth factor receptor (EGFR) in the tyrosine kinase domain through a medicinal plant compound database. J Mol Model, 2012; 18:1241-1254.

102. Lipton A, Villalobo A. EGFR-targeted cancer research: continuing progress and changing views (Editorial). Signal, 2001; 2:2-3.

103. Baselga J, Arteaga CL. Critical update and emerging trends in epidermal growth factor receptor targeting in cancer. J Clin Oncol, 2005; 23:2445-2459.

104. De Lorenzo C, D'Alessio G. Human anti-ErbB2 immunoagents - immunoRNases and compact antibodies. FEBS J, 2009; 276:1527-1535.

105. Markman B, Capdevilla J, Elez E, Tabernero J. New trends in epidermal growth factor receptordirected monoclonal antibodies. Immunotherapy, 2009; 1:965-982.

106. Elloumi J, Jellali K, Jemel I, Aifa S. Monoclonal antibodies as cancer therapeutics. Rec Pat Biotechnol, 2012; 6:45-56.

107. Omidfar K, Shirvani Z. Single domain antibodies: a new concept for epidermal growth factor receptor and EGFRvIII targeting. DNA Cell Biol, 2012; 1015-1026.

108. King CR, Kasprzyk PG, Fischer PH, Bird RE, Turner NA. Preclinical testing of an anti-erbB-2 recombinant toxin. Breast Cancer Res Treat, 1996; 38:19-25.

109. Altintas I, Kok RJ, Schiffelers RM. Targeting epidermal growth factor receptor in tumors: from conventional antibodies via heavy chain-only antibodies to nanobodies. Eur J Pharm Sci, 2012; 45:399-407.

110. Mellinghoff IK, Cloughesy TF, Mischel PS. PTEN-mediated resistance to epidermal growth factor receptor kinase inhibitors. Clin Cancer Res, 2007; 13:378-381.

111. Engelman JA, Jänne PA. Mechanisms of acquired resistance to epidermal growth factor receptor tyrosine kinase inhibitors in non-small cell lung cancer. Clin Cancer Res, 2008; 14:2895-2899.
112. Mukohara T. Mechanisms of resistance to antihuman epidermal growth factor receptor 2 agents in breast cancer. Cancer Sci, 2011; 102:1-8.

113. Ayoola A, Barochia A, Belani K, Belani CP. Primary and acquired resistance to epidermal growth factor receptor tyrosine kinase inhibitors in non-small cell lung cancer: an update. Cancer Invest, 2012; 30:433-446.

114. Schneider JW, Chang AY, Rocco TP. Cardiotoxicity in signal transduction therapeutics: erbB2 antibodies and the heart. Semin Oncol, 2001; 28:18-26.

115. Chaudhary P, Gaira A. Cardiovascular effects of EGFR (epidermal growth factor receptor) monoclonal antibodies. Cardiovasc Hematol Agents Med Chem, 2010; 8:156-163.

116. Yamane K, Toyoshima C, Nishimura S. Ligandinduced functions of the epidermal growth factor receptor require the positively charged region asymmetrically distributed across plasma membrane. Biochem Biophys Res Commun, 1992; 184:1301-1310.

117. Red Brewer M, Choi SH, Alvarado D, Moravcevic K, Pozzi A, Lemmon MA, Carpenter G. The juxtamembrane region of the EGF receptor functions as an activation domain. Mol Cell, 2009; 34:641-651.

118. He L, Hristova K. Consequences of replacing EGFR juxtamembrane domain with an unstructured sequence. Sci Rep, 2012; 2:854.

119. Jura N, Endres NF, Engel K, Deindl S, Das R, Lamers MH, Wemmer DE, Zhang X, Kuriyan J. Mechanism for activation of the EGF receptor catalytic domain by the juxtamembrane segment. Cell, 2009; 137:1293-1307.

120. Park SW, Chung NG, Han JY, Eom HS, Yoo NJ, Lee SH. Somatic mutations of EGFR, ERBB2, ERBB3 and ERBB4 in juxtamembrane activating domains are rare in non-small cell lung cancers. Acta Pathol Microbiol Immunol Scand, 2009; 118:83-84.

121. Arjona D, Bello MJ, Alonso ME, GonzálezGómez P, Lomas J, Aminoso C, López-Marín I, Isla A, de Campos JM, Vaquero J, Villalobo A, Rey JA. Molecular analysis of the erbB gene family calmodulin-binding domain and calmodulin-like domain in astrocytic gliomas. Int J Oncol, 2004; 25:1489-1494.

122. Boran ADW, Seco J, Jayaraman V, Jayaraman G, Zhao S, Reddy S, Chen Y, Iyengar R. A potential peptide therapeutic derived from the juxtamembrane domain of the epidermal growth factor receptor. PLoS One, 2012; 7:e49702.

123. Ward NE, Gravitt KR, O'Brian CA. Irreversible inactivation of protein kinase $\mathrm{C}$ by a peptidesubstrate analog. J Biol Chem, 1995; 270:80568060 .

124. Hunter T, Ling N, Cooper JA. (1984) Protein kinase $\mathrm{C}$ phosphorylation of the EGF receptor at threonine residue close to the cytoplasmic face of 
the plasma membrane. Nature, 1984; 311:480-483.

125. von Heijne G. The signal peptide. J Membr Biol, 1990; 115:195-201.

126. Lin Y-Z, Yao SY, Veach RA, Torgerson TR, Hawiger J. Inhibition of nuclear translocation of transcription factor NF- $\square$ B by a synthetic peptide containing a cell membrane-permeable motif and nuclear localization sequence. J Biol Chem, 1995; 270:14255-14258.

127. Rojas M, Yao SY, Lin Y-Z. Controlling epidermal growth factor (EGF)-stimulated Ras activation in intact cells by a cell-permeable peptide mimicking phosphorylated EGF receptor. J Biol Chem, 1996; 271:27456-27461.

128. Hsu SC, Hung MC. Characterization of a novel tripartite nuclear localization sequence in the EGFR family. J Biol Chem, 2007; 282:1043210440.

129. Liccardi G, Hartley JA, Hochhauser D. EGFR nuclear translocation modulates DNA repair following cisplatin and ionizing radiation. Cancer Res, 2011; 71:1103-1114.

130. García-Palmero I, Villalobo A. Calmodulin regulates the translocation of Grb7 into the nucleus. FEBS Lett, 2012; 586:1533-1539.

131. Chan DW, Hui WW, Cai PC, Liu MX, Yung MM, Mak CS, Leung TH, Chan KK, Ngan HY.
Targeting GRB7/ERK/FOXM1 signaling pathway impairs aggressiveness of ovarian cancer cells. PLoS One, 2012; 7:e52578.

132. Pero SC, Daly RJ, Krag DN. Grb7-based molecular therapeutics in cancer. Expert Rev Mol Med, 2003; 5:1-11.

133. Pero SC, Oligino L, Daly RJ, Soden AL, Liu C, Roller PP, Li P, Krag DN. Identification of novel non-phosphorylated ligands, which bind selectively to the $\mathrm{SH} 2$ domain of Grb7. J Biol Chem, 2002; 277:11918-11926.

134. Tanaka S, Pero SC, Taguchi K, Shimada M, Mori M, Krag DN, Arii S. Specific peptide ligand for Grb7 signal transduction protein and pancreatic cancer metastasis. J Natl Cancer Inst, 2006; 98:491-498.

135. Ambaye ND, Gunzburg MJ, Lim RCC, Price JT, Wilce MCJ, Wilce JA. Benzopyrazine derivatives: a novel class of growth factor receptor bound protein 7 antagonists. Bioorg Med Chem, 2011; 19:693-701.

136. Ambaye ND, Gunzburg MJ, Lim RCC, Price JT, Wilce MCJ, Wilce JA. The discovery of phenylbenzamide derivatives as grb7-based antitumor agents. ChemMedChem, 2013; 8:280288. 